Bull. Egypt. Soc. Physiol. Sci. Vol. (41) Issue (2), 270- 282

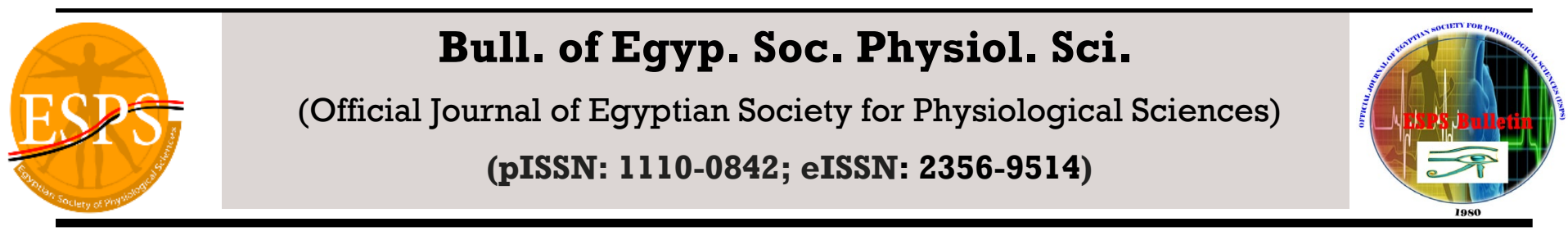

\title{
Protective Effects of Beetroot on Streptozotocin Induced Diabetes in Adult Male Albino Rats
}

Submit Date: July 21, 2020

Accept Date: Sept 3, 2020

Available Online: Jan 10, 2021

\section{Keywords}

- STZ

- Diabetes mellitus

- Beetroot

- Albino rats

\author{
Mohamed Mahmoud Abbas Ali \\ Faculty of Medicine, Alzhar University
}

\begin{abstract}
Background: Diabetes Mellitus is the most common endocrine disorder. It is a pathological state which leads to long term complications causing damage of different tissue and organs as heart and blood vessels. Beetroot have pharmacological activities, including antioxidant, antiinflammatory, antitumor, blood pressure-lowering, neuroprotective and immunomodulatory. Objective: Evaluating beetroot on diabetes induced experimentally in adult male albino rats. Materials and Methods: Sixty adult male albino rats (Rattus norvegicus) were divided into equal four groups as follow: Group I: served as control group, Group II: diabetic group, Group III: normal plus beetroot group and Group IV: Diabetic-beetroot treated group. At the end of experimental period, blood samples were obtained for determination of glycated hemoglobin, blood glucose, serum insulin, aspartate amino transferase (AST), alanine amino transferase (ALT), serum lipid profile (total cholesterol, low density lipoprotein (LDL), high density lipoprotein (HDL) and triglyceride (TG)), malondialdehyde (MDA), catalase, tumor necrosis factor alpha (TNF $\alpha$ ), lactate dehydrogenase, nuclear factor kapp, interleukin 1(IL1) and IL6. Also, pancreas and hepatic samples were obtained for histopathology study. Results: Streptozotocin (STZ) led to significant increase in blood glucose, glycated hemoglobin, cholesterol, TG, LDL, AST, ALT, MDA, TNF, lactate dehydrogenase, nuclear factor kappa, IL-1 and IL-6 associated with significant decrease in serum insulin and catalase levels. Beetroot treatment led to significant improvement of all levels. Conclusion: Beetroot has a protective effect in diabetic rats due to its antioxidant properties.
\end{abstract}

Corresponding author: Mahmoud Abbas, Mohamed Ali, drmohamedali122@gmail.com , MD ,Assistant Professor 01002561051 , Faculty of medicine_Alazhar university 


\section{INTRODUCTION}

Diabetes mellitus (DM) is a complex chronic disease characterized by presence of a state of persistent hyperglycemia that occurs from deficiencies in insulin action, secretion or both and accompanied by greater or lesser impairment in the metabolism of lipids, carbohydrates and proteins (1).

$\mathrm{DM}$ induces pathological changes in the microvasculature, by increasing the capillary basement membrane thickness, leading to the development of diabetic micro-angiopathy (2).

Beta vulgaris is a plant in the Chenopodiaceae family. It is characterized by its multiple cultivated types, the most well-known type is the purple root vegetable that known as beetroot or table garden beet. Beetroot may be eaten raw, baked, boiled or used for juice extraction. Red beets are delicious roasted, pickled, that eaten in salads, or made into soup, which is popular in many Eastern and Central European countries (3).

Beta vulgaris (beetroot) is one of the most important vegetable consumed worldwide. Beetroot can be used to increase exercise stamina and increases running performance (4), it is also used in management of hypertension (5), antiradical, antimicrobial and cytotoxic activities (6). So it has hepatoprotective and antidiabetic potential effects (7).

The present study was designed to evaluate the effect of beetroot on diabetes induced experimentally in adult male albino rats.

\section{MATERIALS AND METHODS}

Animals and experimental design:

Sixty adult male albino rats (Rattus norvegicus) weighing 125 - 165 gm were brought from Nile Pharmaceuticals Company, Cairo, Egypt and chosen to be the model of the present study. They were housed in stainless steel cages $(20 \times 30$ $\times 20 \mathrm{~cm}$ for every five rats) at room temperature, good ventilation and received water and commissural rat chow diet. They were left for two weeks in the laboratory room before the onset of the experiment for acclimatization. Rats were divided into equal 4 groups (15 rats each) as follow;

Group I (Control group): Normal rats fed on commissural rat chow diet and received $0.5 \mathrm{ml}$ distilled water for four weeks.

Group II (Diabetic group): Rats of this group subjected to induction of diabetes by I.P. injection of single dose of $60 \mathrm{mg} / \mathrm{kg}$ body weight of streptozotocin (8) followed by feeding of commissural rat chow diet and all rats received 0.5 $\mathrm{ml}$ distilled water for four weeks.

\section{Group III (Control group plus beetroot):}

Normal rats received oral dose of $250 \mathrm{mg} / \mathrm{Kg}$ body weight of beetroot dissolved in $0.5 \mathrm{ml}$ distilled water for four week (9).

Group IV (Diabetic beetroot-treated group):

Diabetes was induced as group II, followed by oral dose of $250 \mathrm{mg} / \mathrm{Kg}$ body weight of beetroot dissolved in $0.5 \mathrm{ml}$ distilled water for four week (9).

Induction of diabetes: STZ was purchased from Sigma Pharmaceuticals Company in the form of vial contain $100 \mathrm{mg} \mathrm{STZ}$ powder and dissolved in $10 \mathrm{ml}$ saline to prepare $10 \mathrm{ml} \mathrm{STZ} \mathrm{solution} \mathrm{and}$ given in a dose of $60 \mathrm{mg} / \mathrm{kg}$, body weight in 50 
$\mathrm{mM}$ citrate buffer (8), then the animals were allowed to drink 5\% glucose solution overnight. After 72 hours these animals were tested for diabetes using a glucometer (Aquo-Check, Roche). The animals with fasting blood glucose level more than $190 \mathrm{mg} / \mathrm{dl}$ selected for further study (10).

Beetroot leaves were purchased from a local herbal market in Damietta, Damietta governorate, Egypt, in December 2019. The leaves were washed with tap water and crushed for extraction at pharmacology department lab, faculty of pharmacy, Mansoura University. The juice was extracted from the beetroot using a muslin cloth and distilled water and the shaft discarded. The juice obtained was stored in an airtight container ( $5 \mathrm{~kg}$ of beetroot yielded approximately $1.5 \mathrm{~L}$ of juice after extraction) and allowed to settle for 20$30 \mathrm{~min}$. The juice obtained was freeze dried and ready for use. The freeze dried sample was stored at $0^{\circ} \mathrm{C}$ until ready for use (9).

Ethyl Ether (Analar, Nile Pharmaceutical): For anesthesia.

Blood sample: At the end of experimental period, all rats were fasted overnight and anesthetized by placing in an anesthetic box filled with ether vapor. Ether vapor was maintained by periodically applying liquid ether to a cotton wool on the base of the box. Blood was withdrawn from the retroorbital plexus using heparinized capillary tube for determination of blood glucose (11), and glycated hemoglobin levels (12). To obtain serum, blood was left to clot and centrifuged at 5000 rate per minute for 10 minutes. Serum was sucked out into Eppendorf tubes and stored frozen at $-20^{\circ} \mathrm{C}(13)$ until assayed for determination of determination of aspartate amino transferase (AST) (14), alanine amino transferase (ALT) (14), total cholesterol
(15), Triglyceride (TG) (16), high density lipoprotein (HDL) (15), low density lipo-protein (LDL) (17), serum insulin level (18), malondialdehyde (MDA) (19), catalase (20), tumor necrosis factor alpha $(\mathrm{TNF} \alpha)(21)$, lactate dehydrogenase (22), nuclear factor kappa (23) and interleukin 1(IL1) (24) and IL6 (25).

Pancreas and liver were excised for histopathological examination which preserved in $10 \%$ formalin solution. Paraffin blocks were made for the tissue samples and different sections were obtained and slides were stained with hematoxyline and eosin ( $\mathrm{Hx}$ and $\mathrm{E})$ stains and examined using a light microscope (at General pathology department, faculty of medicine, AlAzhar University, Damietta).

Statistical analysis: Data input and analysis were done using Statistical Package for the Social Sciences (SPSS) version "24" computer program. All results were expressed as mean \pm standard deviation. Mean values of the different groups were compared. Least significant difference (LSD) post hoc analysis was used to identify significantly different mean values. $\mathrm{P}$ value $<0.05$ was accepted to denote a significant difference.

\section{RESULTS}

Results of the present study showed that induction of diabetes led to significant increase in the mean value of blood glucose level, glycated hemoglobin level, AST, ALT, serum cholesterol level, serum triglyceride level, serum LDL level, serum MDA, TNF alpha, lactate dehydrogenase, nuclear factor kappa, IL1 and IL6 level in diabetic group (Group II) associated with significant decrease in the mean value of body weight, serum HDL, insulin and catalase level. Administration of 
beetroot to normal rats led to insignificant changes in all sample levels (Table 1).

Administration of beetroot to diabetic rats led to significant decrease in the mean value of blood glucose level, glycated hemoglobin level, AST, ALT, serum cholesterol level, serum triglyceride level, serum LDL level, serum MDA, TNF alpha, lactate dehydrogenase, nuclear factor kappa, IL1 and IL6 level, associated with significant increase in the mean value of body weight, serum HDL, insulin and catalase level (Table 2).

Table (1): Effects of STZ on studied groups (Mean \pm SD).

\begin{tabular}{|c|c|c|c|}
\hline $\begin{array}{l}\text { Groups } \\
\text { Parameters }\end{array}$ & Group I & Group II & Group III \\
\hline Body weight & $220.87 \pm 8.71$ & $106.07 \pm 9.08 *$ & $\mathbf{2 2 2 . 1} \pm 8.27$ \\
\hline Blood Glucose (mg/dl) & $99.0 \pm 10.72$ & $333.27 \pm 24.48 *$ & $100.07 \pm 9.02$ \\
\hline Serum insulin $(\mu \mathrm{IU} / \mathrm{L})$ & $10.14 \pm 0.62$ & $3.9 \pm 0.37 *$ & $10.06 \pm 0.31$ \\
\hline Glycated hemoglobin (\%) & $5.08 \pm 0.38$ & $10.7 \pm 0.42 *$ & $4.72 \pm 0.62$ \\
\hline Cholesterol (mg/dl) & $99.6 \pm 6.78$ & $130.0 \pm 4.42 *$ & $98.07 \pm 5.52$ \\
\hline TGs (mg/dl) & $90.13 \pm 4.1$ & $115.87 \pm 5.9 *$ & $91.0 \pm 4.63$ \\
\hline HDL (mg/dl) & $41.13 \pm 2.41$ & $31.27 \pm 2.4 *$ & $39.53 \pm 1.85$ \\
\hline LDL (mg/dl) & $40.44 \pm 6.81$ & $75.56 \pm 6.15 \%$ & $40.33 \pm 5.89$ \\
\hline AST (U/L) & $25.4 \pm 2.29$ & $67.33 \pm 5.16^{*}$ & $25.13 \pm 2.56$ \\
\hline $\operatorname{ALT}(\mathrm{U} / \mathrm{L})$ & $21.47 \pm 2.26$ & $49.07 \pm 4.36 *$ & $21.8 \pm 3.03$ \\
\hline MDA (nmol/l) & $21.2 \pm 3.17$ & $45.6 \pm 3.6^{*}$ & $22.93 \pm 1.98$ \\
\hline Catalase (mg/dl) & $36.47 \pm 4.59$ & $26.13 \pm 1.95 *$ & $34.13 \pm 2.59$ \\
\hline TNF (Pg/ml) & $53.27 \pm 3.19$ & $96.67 \pm 4.59 \%$ & $52.67 \pm 5.15$ \\
\hline Lactate dehydrogenase (U/L) & $148.4 \pm 6.89$ & $253.2 \pm 7.58 *$ & $145.47 \pm 7.16$ \\
\hline Nuclear factor kappa & $0.87 \pm 0.17$ & $2.21 \pm 0.23 *$ & $0.86 \pm 0.15$ \\
\hline IL-1 (Pg/ml) & $2.39 \pm 0.24$ & $5.47 \pm 0.39 *$ & $2.31 \pm 0.202$ \\
\hline IL-6 (Pg/ml) & $3.46 \pm 0.32$ & $7.04 \pm 0.48 *$ & $3.68 \pm 0.34$ \\
\hline
\end{tabular}

* indicate significance compared to group I Group II: Diabetic group.

Group I: control group.

Group III: Control- beetroot group.

Table (2): Effects of beetroot on diabetic groups (Mean \pm SD).

\begin{tabular}{|c|c|c|}
\hline $\begin{array}{l}\text { Groups } \\
\text { Parameters }\end{array}$ & Group II & Group IV \\
\hline Body weight & $106.07 \pm 9.08$ & $145.53 \pm 7.33 *$ \\
\hline Blood Glucose (mg/dl) & $333.27 \pm 24.48$ & $222.13 \pm 17.71 *$ \\
\hline Serum insulin $(\mu \mathrm{IU} / \mathrm{L})$ & $3.9 \pm 0.37$ & $6.28 \pm 0.38 *$ \\
\hline Glycated hemoglobin (\%) & $10.7 \pm 0.42$ & $6.94 \pm 0.66 *$ \\
\hline Cholesterol (mg/dl) & $130.0 \pm 4.42$ & $112.47 \pm 5.89 *$ \\
\hline TGs (mg/dl) & $115.87 \pm 5.9$ & $95.27 \pm 5.0 *$ \\
\hline HDL (mg/dl) & $31.27 \pm 2.4$ & $34.8 \pm 2.34 *$ \\
\hline LDL (mg/dl) & $75.56 \pm 6.15$ & $58.49 \pm 6.73 *$ \\
\hline $\operatorname{AST}(\mathrm{U} / \mathrm{L})$ & $67.33 \pm 5.16$ & 47.73 $\pm 3.59 *$ \\
\hline $\operatorname{ALT}(\mathrm{U} / \mathrm{L})$ & $49.07 \pm 4.36$ & $39.4 \pm 1.99 *$ \\
\hline MDA (nmol/l) & $45.6 \pm 3.6$ & $30.53 \pm 4.05 *$ \\
\hline Catalase (mg/dl) & $26.13 \pm 1.95$ & $29.73 \pm 1.39 *$ \\
\hline TNF (Pg/ml) & $96.67 \pm 4.59$ & $76.33 \pm 5.27 *$ \\
\hline Lactate dehydrogenase (U/L) & $253.2 \pm 7.58$ & $200.8 \pm 8.8 *$ \\
\hline Nuclear factor kappa & $2.21 \pm 0.23$ & $1.66 \pm 0.15 *$ \\
\hline IL-1 (Pg/ml) & $5.47 \pm 0.39$ & $3.97 \pm 0.48 *$ \\
\hline IL-6 (Pg/ml) & $7.04 \pm 0.48$ & $6.18 \pm 0.59^{*}$ \\
\hline
\end{tabular}

Group II: Diabetic group

* indicate significance compared to group II.
Group IV: Diabetic- beetroot treated group. 


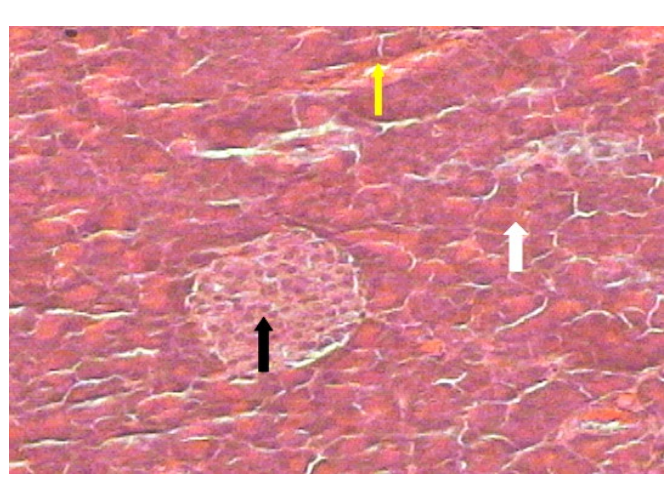

Figure (1): section of the pancreas shows normal pancreatic islets (black arrow), normal pancreatic acini (white arrow) and normal blood vessels (yellow arrow) of the control group $(\mathbf{H} \& \mathbf{E}-\times \mathbf{4 0 0})$.

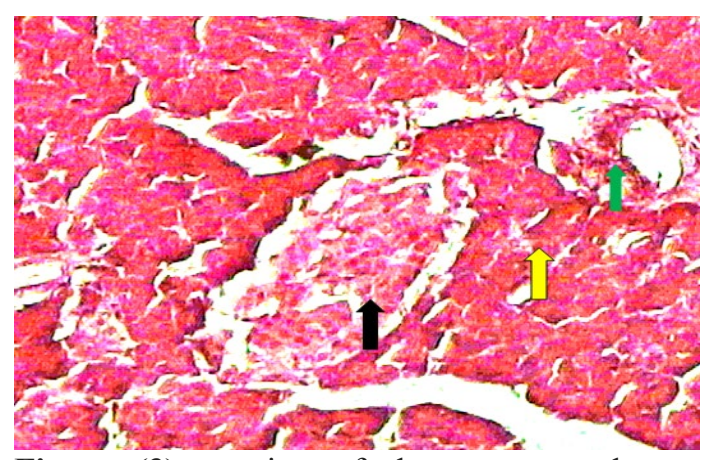

Figure (3): section of the pancreas shows normal pancreatic islets (black arrow), normal pancreatic acini (yellow arrow) and normal blood vessels (green arrow) of the control plus beetroot group $(\mathbf{H} \& \mathbf{E}-\times \mathbf{4 0 0})$

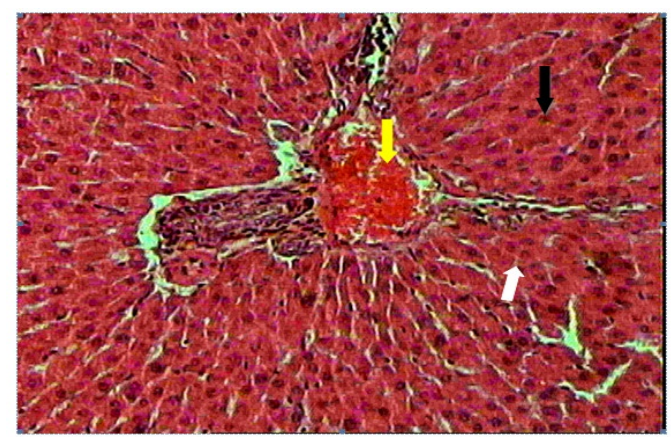

Figure (5): Cross section of the liver shows normal hepatocytes (white arrow), normal blood sinusoids in between cords of hepatocytes (black arrow) and normal central vein (yellow arrow) of the control group (H\&E- $\times \mathbf{4 0 0})$.

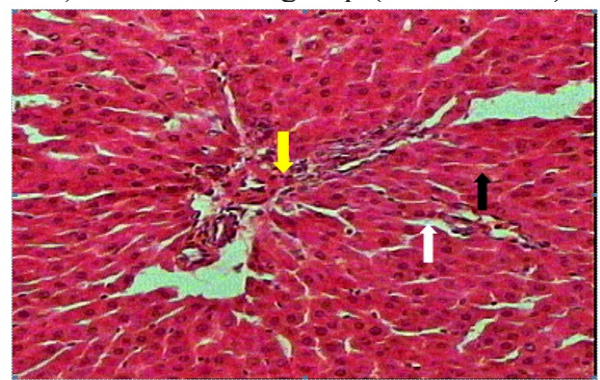

Figure (7): Cross section of the liver shows normal hepatocytes (white arrow), normal blood sinusoids in between cords of hepatocytes (black arrow) and normal central vein (yellow arrow) of the control beetroot group (H\&E- $\times \mathbf{4 0 0})$.

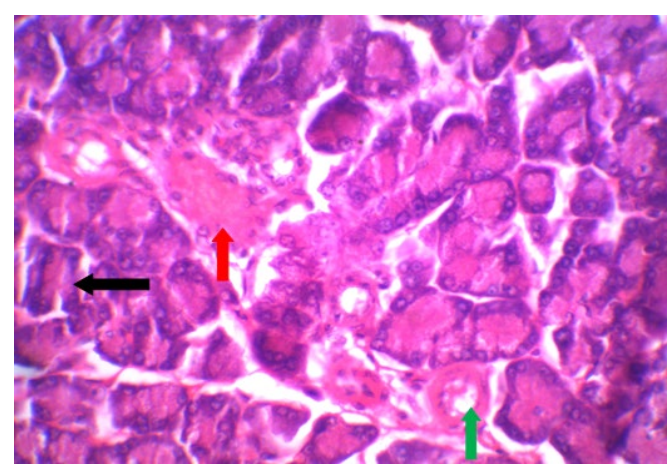

Figure (2): Section in the pancreas shows distortion and atrophy of pancreatic islets (red arrow), normal pancreatic acini (black arrow) and normal pancreatic blood vessels (green arrow) of the diabetic group $(\mathbf{H} \& \mathbf{E}-\times \mathbf{4 0 0})$.

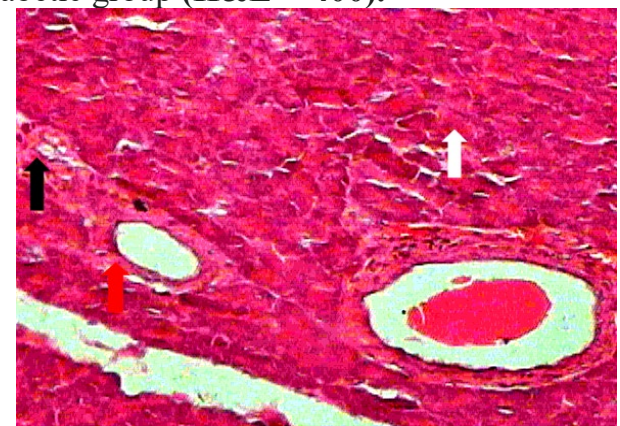

Figure (4): section of the pancreas shows improved atrophied pancreatic islets (black arrow), normal pancreatic acini (red arrow) and normal blood vessels (white arrow) of the diabetic beetroot treated group (H\&E- $\times \mathbf{4 0 0})$

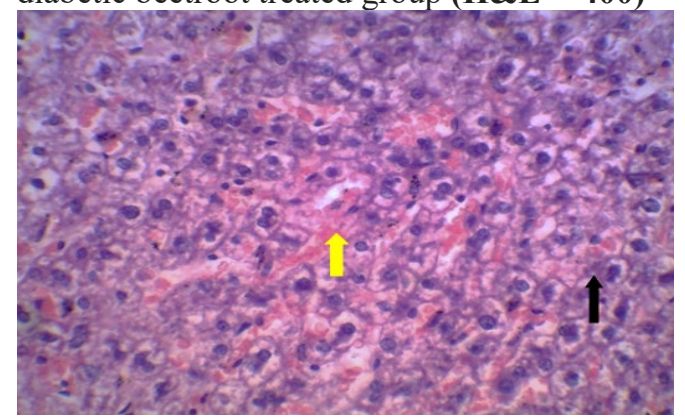

Figure (6): Section of the liver shows marked vaculations of hepatocytes (black arrow) with congested blood vessels (yellow arrow) of the diabetic group $(\mathbf{H} \& \mathbf{E}-\mathbf{4} \mathbf{4 0 0})$.

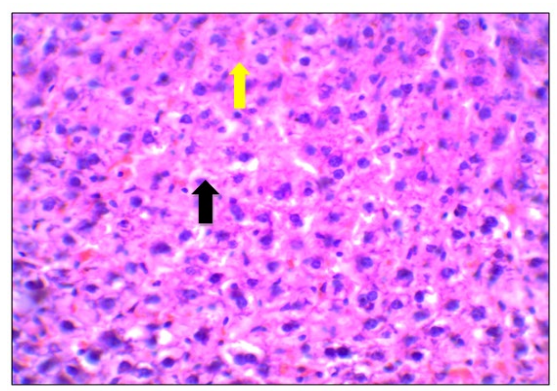

Figure (8): Section of the liver shows few vaculations of hepatocytes (black arrow) with congested blood vessels (yellow arrow) of the diabetic- beetroot treated group $(\mathbf{H} \& \mathbf{E}-\times \mathbf{4 0 0})$. 


\section{DISCUSSION}

The present work was designed to evaluate the effect of beetroot on diabetes induced experimentally in adult male albino rats.

Results of the present work showed that STZ injection led to significant decreased body weight in diabetic rats when compared with normal. These results were in agreement with the findings of Yang and Hyung-Sub (26) who observed that marked decrease body weight in streptozotocin induced diabetic rats, due to absolute or relative deficiency of insulin or due to decreased protein synthesis production in all tissues (27).

Soliman (28) reported that severe body weight loss in untreated diabetic rats. This loss may be due to fats and proteins degradation or catabolism. So, muscle wasting resulted from increased catabolic reactions which act the important cause for weight loss in diabetic rats.

Results of the present work showed that STZ injection led to significant increase of blood glucose level and glycated hemoglobin associated with significant decrease in insulin level in diabetic group comparing to the control group. These results were in agreement with Sekkin et al. (29) who noticed that single injection of STZ leads to DM development that diagnosed by elevated blood glucose, glycated hemoglobin (HbAlc) and decreased serum insulin levels. This occurred due to the damage of islets cells , $\beta$ cells destruction within twenty four hour and also, triggering of inflammatory process leading to macrophage and subsequent lymphocyte infiltration caused by STZ. Oxidative damage induced by STZ in rats is closely associated with chronic inflammation leading to potential tissue damage (30).
In the present study, there were significant increases in cholesterol, triglyceride (TG) and low density lipoprotein (LDL), associated with significant decrease in high density lipoprotein (HDL) in diabetic rats comparing to the control rats. These results were compatible with Saleh \& maged (31) who found that significant elevations of cholesterol, LDL and TGs levels in diabetic rats when compared with normal one.

The present study showed that AST and ALT level increased significantly in diabetic rats when compare with normal rats. These results were compatible with the findings of Makena et al. (32) which reported that ALT and AST increase in diabetic group than normal group

Diabetes mellitus can be induced hepatic injury, that leading to glucogenesis and elevation of the concentrations of protein. ALT and AST in $\mathrm{DM}$ are associated with the conversion of amino acids to keto acids (33).

In the present study, MDA, lactate dehydrogenase, TNF, IL-1 and IL-6 increased significantly in diabetic rats comparing to normal associated with significant decreased of catalase. These results agreed with Elsawy and Emara (34) who reported that increased proinflammatory cytokines such as IL-1, IL-6, MDA and TNF- $\alpha$, due to increased oxidative stress status or a decrease in antioxidant defense systems in DM.

Also, the present study was in agreement with Edrees et al. (35) who reported that diabetic rats associated with increased TNF- $\alpha$ due to oxidative stress leading to abnormal cytokine production as TNF- $\alpha$ that produced by the liver in response to inflammation. El-Komy and Mouafi (36) found that oxidative damages associated with increased production of TNF- $\alpha$ that stimulate 
nuclear factor kappa B (NF-kB) production and neutrophil infiltration. TNF- $\alpha$ plays a important role in the activation of caspases which cause cell apoptosis induction (37).

Diabetic rats had highest level of TNF- $\alpha$. This was due to inflammatory reaction of TNF- $\alpha$ led to apoptosis of $\beta$-cell. High concentration of inflammatory cells may lead to $\beta$-cell apoptosis which may lead to either lowering in number of cells of insulin-producer or insulin decrease (38).

In the present study, diabetic rats associated with significant increase of MDA, lactate dehydrogenase, in addition to significant decreased of catalase level. These results were inagreement with Elbe et al. (39) and Lo et al. (40) who reported a decreased catalase level and elevated level of MDA in diabetic rats. The decrease in the activity of these antioxidants can lead to increase superoxide anion and hydrogen peroxide in biological systems, which in turn generate hydroxyl radicals resulting in lipid peroxidation. Catalase is responsible for the reduction of $\mathrm{H} 2 \mathrm{O} 2$ for protecting cells against highly reactive $\mathrm{OH}$ radicals. Oxidative stress in diabetes is caused by hyperglycemia inducing increased free radical formation (27).

In the present study, beetroot led to significant increase of body weight. The results agreed with Choi et al. (41) who reported that B. vulgaris leaves extract led to significant increase in bodyweight in the diabetic rats due to positive anabolic effect of $\mathrm{B}$. vulgaris through improving lipid and glucose metabolism.

In the present study, beetroot led to significant decreased of blood glucose, glycated hemoglobin associated with significant decreased insulin level. Ninfali and Angelino (42) noticed the administrated extract of Beta vulgaris to DM reduced blood glucose levels due to the pancreatic beta-cells regeneration.

Accordingly, Kumar et al. (43) concluded that the ethanolic extract of beetroot possessed a potential anti-diabetic activity against streptozocin induced diabetic rats. According to Olumese and Oboh (44) beetroot juice administration for six weeks led to lowering blood glucose level by inhibition of carbohydrate digestion and glucose absorption in the intestine, and the modulation of glucose release from the liver.

Results of the present study showed that beetroot administration led to significant decreased of ALT and AST, lipid levels and these results compatible with Abdul Bari et al. (45) andAmnah and Alushaibani (46) who noticed that cholesterol, total lipids and liver enzymes decreased significantly in diabetic rats with consumption of beetroot powder. Nouri et al. (47) found that liver enzymes decreased in diabetic rats treated with beetroot.

In addition, Iahtisham et al. (48) reported that the hepatoprotective effect of beetroot due to antiradical scavenging activity of the extract. The antiradical activity of beetroot may be due to its high source of polyphenols and flavonoids, such as betalains. Further evidence supports the ability of polyphenols to enhance detoxifying/antioxidant enzymes of Phase II, exerting hepatoprotective effect (49).

Similarly, Singh et al. (50) reported that the beetroot juice consumption lowered the lipid profile i.e. total cholesterol, LDL, triglycerides levels and also significantly increased HDL levels. Beetroot has a hepatoprotective effect due to the 
presence of active compound betaine in it that having antioxidant properties.

In the same context, Clifford et al. (51) reported that beetroot had protective effects on vascular system and manage cardiovascular disease by reducing the cholesterol and oxidized LDL cholesterol. According to Ninfali and Angelino (42) beetroot ingestion has a beneficial physiological effect for atherosclerosis disease. This effect was due to its high concentration of betalains that reduced the homocysteine concentration and regulated the vascular homeostasis (52).

In the present study, beetroot administration led to significant decreased of MDA. These results agreed with Fustinoni-Reis et al. (53) who noticed that MDA decreased significantly in beetroot treated diabetes. This effect may be due to the antioxidant activity of polyphenols present in beetroot.

Also, Albalawi et al. (54) showed that administration of beetroot extract led to significant decrease in the level of liver tissue NF-kB and TNF- $\alpha$. El Gamal et al. (55) reported oral administration of beetroot ethanol extract for four weeks led to significant decreased of several proinflammatory mediators as MDA, Il-6, TNF- $\alpha$ and $\mathrm{NF}-\kappa \mathrm{B}$ and also led to significant increased catalase level due to anti-inflammatory protection effect.

The consumption of beetroot has been associated with the prevention of oxidative reactions, through the inhibition of pro-oxidants and the activation of the endogenous antioxidant system (51). The increased levels of antioxidant enzymes after beetroot administration are due to its ability to activate nuclear factor (erythroid-derived 2)-like 2 which further activates the gene expression of antioxidant enzymes (56).

In the present study, the histo-pathological examination revealed that induction of diabetes led to distortion and atrophy of pancreatic islets and beetroot administration led to improved atrophied pancreatic islets. My results agreed with Indumathi et al. (57) and Han et al. (58) who reported that STZ induced diabetes led to necrotic changes and degranulation of pancreatic islets and beetroots administration restore the islet cells histology in pancreas. Streptozotocin attacks the pancreatic $\beta$ cells via glucose transporter (GLUT 2) led to damaged $\beta$-cells by DNA alkylation. The production of superoxide radicals with free radicals associated with $\beta$-cells damage. Free radicals play an important role in the development of diabetes mellitus by causing the partial destruction of $\beta$-cells (59).

In the present study, induction of diabetes led to marked vaculations of hepatocytes with congested blood vessels and beetroot administration led to decreased vaculations of hepatocytes. These results compatible with Olumese and Oboh (9) and Indumathi et al. (57) who reported that STZ induced diabetes led to vaculations of hepatocytes with dilated sinusoids and beetroots administration decrease the pathological changes of liver and improved hepatic architecture.

Beetroot prevented liver damage through its dual ability to scavenge reactive oxygen species and activate nuclear factor erythroid 2-related factor 2. The antioxidant efficacy of beetroot has been confirmed through its ability to scavenge 2, 2-Diphenyl-1-picrylhydrazyl radicals in vitro (56). 
Conclusion: Beetroat has a marked enhancing effects on blood glucose, insulin, blood urea, creatinine, lipid profile adult male albino rats. This might be due to hepatoprotective, hypoglycemic and lipid-lowering effect. These effects of Beetroot could improve diabetic mortality and morbidity.

\section{REFERENCES}

\section{1-Trikkalinou A, Papazafropoulou AK and}

Melidonis A. Type 2 diabetes and quality of life. World J Diabetes. 2017; 8(4): 120-129.

2- Chawla A, Chawla R, Jaggi S. Microvasular and macrovascular complications in diabetes mellitus: Distinct or continuum?. Indian J Endocr Metab. 2016; 20(4):546-553.

3- Babarykin D, Smirnova G, Pundinsh I, Vasiljeva S, Krumina G, Agejchenko V. Red Beet (Beta vulgaris ) Impact on Human Health. Journal of Biosciences and Medicines. 2019; 7: 61-79.

4- Wylie LJ, Kelly J, Bailey SJ, Blackwell JR, Skiba PF, Winyard PG. Beetroot juice and exercise: pharmacodynamic and dose response relationships. J Appl Physiol. 2013; 115:32536.

5- Siervo M, Lara J, Ogbonmwan I, Mathers JC. Inorganic nitrate and beetroot juice supplementation reduces blood pressure in adults: a systematic review and meta-analysis. $\mathrm{J}$ Nutr., 2013; 143: 818-826.

6- Vulic JJ, Cebovic TN, Canadanovic VM, Cetkovic GS, Djilas SM, CanadanovicBrunet J. Antiradical, antimicrobial and cytotoxic activities of commercial beetroot pomace. Food Funct. 2013; 4:713-721.

7- Jaiswal A, Ganeshpurkar A, Awasthi A, Bansal D, Dubey N. Protective Effects of
Beetroot Extract against Phenyl Hydrazine Induced Anemia in Rats. Phog J. 2014; 6(5): 9-15.

\section{8- Roy S, Metya S, Sannigrahi S, Rahaman N,} Ahmed F. Treatment with ferulic acid to rats with streptozotocininduced diabetes: effects on oxidative stress, pro-inflammatory cytokines, and apoptosis in the pancreatic $\beta$ cell. Endocrine. 2013; 44: 369-379.

9- Olumese FE, Oboh HA. Hepato-protective effect of beetroot juice on liver injury in male Sprague-Dawley rats. Ann Trop Pathol. 2018; 9: 83-88.

10- Park JJ, Kang KL. Effect of 980-nm GaAlAs diode laser irradiation on healing of extraction sockets in streptozotocin-induced diabetic rats: a pilot study. Lasers Med Sci. 2012; 27(1): 223230.

11- Braham D, Trinde P. An improved colour reagent for the determination of blood glucose by the oxidase system. Analyst. 1972; 97: 142145.

12- Inouye M, Mio T, Sumino K. Glycated hemoglobin and lipid peroxidation in erythrocytes of diabetic patients. Metabolism. 1999; 48 (2): 205-209.

13- Shermer S. Rats haemopiotic system, in the blood morphology of laboratory animals. Pbl. F.A. Davis Co., Philadelphia U.S.A., 1968; Chap. 2: 42-43.

14- Reitman S, Frankel S. A colorimetric method for the determination of serum glutamic oxalacetic and glutamic pyruvic transaminases. Am J Clin Pathol. 1957; 28(1):56-63.

15- Tietz N. Tietz text book of clinical chemistry, 5 th Ed.WB Saunders. Co. London, Philadelphia. 2011; 796-798. 
16- Nägele U, Hägele EO, Sauer G, Wiedemann E, Lehmann P, Wahlefeld AW, et al. Reagent for the enzymatic determination of serum total triglycerides with improved lipolytic efficiency. J. Clin. Chem. Clin. Biochem. 1984; 22(2): 165-174.

17- Friedewald WT, Levy RI, Fredrickson DS. Estimation of the concentration of low-density lipoprotein cholesterol in plasma, without use of the preparative ultracentrifuge. Clin. Chem., 1972; 18:499-502.

18- Rydtren T, Sandler S. Efficacy of 1400 W, a novel inhibitor of inducible nitric oxide synthase, in preventing interleukin-lbetainduced suppression of pancreatic islet function in vitro and multiple low-dose streptozotocininduced diabetes in vivo. Eur. J. Endocrinol. 2002; 147:543- 551.

19- Erdelmeier I, Gérard-Monnier D, Yadan JC, Chaudière J. Reactions of N-methyl-2phenylindole with malondialdehyde and 4hydroxyalkenals. Mechanistic aspects of the colorimetric assay of lipid peroxidation. Chem Res Toxicol. 1998; 11(10):1184-94.

20- Sinha AK. Colorimetric assay of catalase. Anal Biochem., 1972; 47(2):389-94.

21- Aggarwal BB, Natarajan K. Tumor necrosis factors: developments during the last decade. (Eur Cytokine Netw., 1996; 7(2):93-124.

22- Kumar V, Gill KD. Determination of Total Lactate Dehydrogenase Activity in Serum Sample. In: Basic Concepts in Clinical Biochemistry: A Practical Guide. Springer, Singapore. 2018; pp 129-130

23- Chen W, Zheng Z, Duan J. Quantitation of nuclear factor kappa B activation in pancreatic acinar cells during rat acute pancreatitis by flow cytometry. Int J Clin Exp Med. 2015; 28(6):10143-10151.

24- Church D, Cook G, McDermott $M$. inflammasomes and interleukin $1 \beta$ in inflammatory disorders." Nature Clinical Practice Rheumatology, 2008; 4 (8): 34-42.

25- Wang CW, Manne U, Reddy VB, Kapoor R. Quantitative Estimation of IL-6 in Serum/Plasma Samples Using a Rapid and Cost-Effective Fiber-Optic dip-probe. Proc SPIE Int Soc Opt Eng. 2010; 7559.

26- Yang D, Hyung-Sub K. anti-Diabetic Effect of Cotreatment with Quercetin and Resveratrol in Streptozotocin-Induced Diabetic Rats. Biomol Ther (Seoul). 2018; 26(2): 130-138.

27- Sadri H, Goodarzi M, Salemi Z, Morteza S. antioxidant Effects of Biochanin $a$ in Streptozotocin Induced Diabetic Rats. Braz. arch. biol. Technol. 2017; 60:11-19.

28- Soliman AM. Potential impact of Paracentrotus lividus extract on diabetic rat models induced by high fat diet/streptozotocin. The Journal of Basic \& applied Zoology. 2016; 77(10): 8-20.

29- Sekkin S, Ipek E, Boyacioğlu M, Kum C. DNA protective and antioxidative effects of melatonin in streptozotocin-induced diabetic rats. Turkish Journal of Biology. 2015; 39: 932940.

30- Xu YJ, Tappia PS, Neki NS, Dhalla NS. Prevention of diabetes induced cardiovascular complications upon treatment with antioxidants. Heart Fail Rev. 2014; 19: 113121.

31- Saleh N M, maged MY (2010): physiological changes associated with streptozotocin induced 
experimental diabetic rats. Journal of Al- Azhar university- Gaza. 2010; 12: 31-35.

32- Makena W, Hamman WO, Buraimoh AA, Dibal NI and Obaje SG. Therapeutic effects of balanitoside in streptozotocin-induced diabetic rats. J Taibah Univ Med Sc. 2018; 13(4):402-406.

33- Qian K, Zhong S, Xie K, Yu D, Yang R and Da-Wei G. Hepatoprotective Potential of Sargassum muticum against STZ-Induced Diabetic Liver Damage in Wistar Rats by Inhibiting Cytokines and the Apoptosis Pathway. Analytical Cellular Pathology. 2019; 19: ID 7958701.

34- Elsawy M, Emara E. The impact of ghrelin on oxidative stress and inflammatory markers on the liver of diabetic rats. Tanta Med J. 2016; 44:163-169.

35- Edrees HM, Ayman E, Yousif M. Hypoglycemic and anti-Inflammatory Effect of Gold Nanoparticles in Streptozotocin-Induced Type 1 Diabetes in Experimental Rats. International Journal of Diabetes Research. 2017; 6(1): 16-23.

36- El-Komy MA, Mouafi FE (2016): Mitigating effect of avicenna marina on indomethacin induced gastric ulcer in male albino rats. Egyptian Journal of Basic and applied Sciences. 2016; 3: 155-163.

37- Li W, Wang X, Zhang H, He Z, Zhi W, Liu F et al. anti-ulcerogenic effect of cavidine against ethanol-induced acute gastric ulcer in mice and possible underlying mechanism. International Immunopharmacology. 2016; 38: 450-459.

38- Mardiaha B, Zakariaa FR, Prangdimurtia E, Damanikc R. anti-inflammatory of Purple
Roselle Extract in Diabetic Rats Induced by Streptozotocin. Procedia Food Science. 2015; 3 (15): $182-189$.

39- Elbe H, Esrefoglu M, Vardi N, Taslidere E, Ozerol E, Tanbek K. Melatonin, quercetin and resveratrol attenuates oxidative hepatocellular injury in streptozotocin-induced diabetic rats. Hum. Exp. Toxicol. 2015; 34: 859-868.

\section{0- Lo C, Shyh-Hsiang L, Jung-Su C, Yi-Wen}

C. Effects of Melatonin on Glucose Homeostasis, antioxidant ability, and adipokine Secretion in ICR Mice with Na/STZ-Induced Hyperglycemia. Nutrients. 2017; 9 (1187): 113.

41- Choi JS, Islam MN, Ali MY, Kim YM, Park HJ, Sohn HS, et al. The effects of Cglycosylation of luteolin on its antioxidant, anti-Alzheimer's disease, anti-diabetic, and anti-inflammatory activities, Arch. Pharm. Res. 2014; 37 (10): 1354-1363.

42- Ninfali P, Angelino D. Nutritional and Functional Potential of Beta vulgaris cicla and rubra. Fitoterapia. 2013; 89: 188-199.

43- Kumar SP, Bhaumik A, Chopra M, Neelima-Devil K. Evaluation of Anti diabetic activity of Ethanolic Extract of Beet Root (EEBT- Beta vulgaris) against Streptozocin induced diabetic Rats. Journal of Drug Discovery and Therapeutics. 2016; 4(37): 0106.

44- Olumese FE, Oboh HA. Effects of Daily Intake of Beetroot Juice on Blood Glucose and Hormones in Young Healthy Subjects.Nig. Qt J. Hosp. Med. 2016; 26(2) :455-462.

45- Abdul Bari MA, Albadri MH, Hussein FH. The protective effects of beetroot against Dexamethasone induced damage in liver, 
kidney and Hyper-lipidemic effects in mice .Wipmr. 2018; 4(11):60-68.

46- Amnah A, Alsuhaibani MA. Nutritional, Sensory and Biological Study of Biscuits Fortified With Red Beet Roots. Life Sci J. 2013; 10(3):1579-1584.

47- Nouri D, Althalmawi H, Faifi L. Study on the growth factors and hepatoprotective effect of Beta vulgaris L. in male Wistar rat. Journal of Health Sciences and Nursing. 2017; 2(1):1827.

48- Iahtisham H, Butt MS, Randhawa MA, Shahid M. Hepatoprotective effects of red beetroot-based beverages against CC14-induced hepatic stress in Sprague Dawley rats. J Food Biochem. 2019; 43(12):e13057.

49- Albrahim T, Alonazi MA. Role of Beetroot (Beta vulgaris) Juice on Chronic Nanotoxicity of Silver Nanoparticle-Induced Hepatotoxicity in Male Rats. International Journal of Nanomedicine. 2020; 15: 3471-3482

50- Singh A, Verma S, Singh V, jappa C, Roopa N, Raju P. Beetroot Juice Supplementation Increases High Density LipoproteinCholesterol and Reduces Oxidative Stress in Physically Active Individuals. Journal of Pharmacy and Nutrition Sciences, 2015; 5(3):179-185.

51- Clifford T, Howatson G, West JD, Stevenson JE. The potential benefits of red beetroot supplementation in health and disease. Nutrients. 2015; 7: 2801-2822.

52- Amin AR, Kassab RB, Abdel Moneim AE, Amin HK. Comparison Among Garlic, Berberine, Resveratrol, Hibiscus sabdariffa, Genus Zizyphus, Hesperidin, Red Beetroot, Catha edulis, Portulaca oleracea, and Mulberry
Leaves in the Treatment of Hypertension and Type 2 DM: A Comprehensive Review. Natural Product Communications. 2020; 15(4): $1-24$.

\section{3- Fustinoni-Reis AM, Arruda SF, Dourado} LP, da Cunha MS, Siqueira EM. consumption modulates iron homeostasis and prevents iron-induced oxidative stress in the Rat Liver. Nutrients. 2016; 8: 38-41.

54- Albalawi WI, Abdul Majid NA, Sharaf IA. Prophylactic Impact of Beta vulgaris $\mathrm{L}$ in Ameliorating Cyclosporine A-Induced Hepatotoxicity in Rats. International Journal of Pharmaceutical Research \& Allied Sciences. 2019; 8(3): 212-224

55- El Gamal AA, AISaid MS, Raish M, alSohaibani M, al-Massarani SM, Ahmad A, et al. Beetroot (Beta vulgaris L.) extract ameliorates gentamicin-induced nephrotoxicity associated oxidative stress, inflammation, and apoptosis in rodent model. Mediat. Inflamm., 2014; 14: 983-952.

56- Albasher G, Alsaleh AS, Alkubaisi N, Alfarraj S, Alkahtani S, Farhood M, et al. Red Beetroot Extract Abrogates ChlorpyrifosInduced Cortical Damage in Rats. Oxidative Medicine and Cellular Longevity. 2020; 20: 113. ID 2963020:

57- Indumathi D, Sujithra K, Srinivasan S, Vinothkumar V. Ameliorating effect of betanin, a natural chromoalkaloid by modulating hepatic carbohydrate metabolic enzyme activities and glycogen content in streptozotocin - nicotinamide induced experimental rats. Biomedicine \& Pharmacotherapy. 2017; 88 (17): 1069-1079. 
58- Han J, Zhang Z, Yang S, Wang J, Yang X,

Tan D. Betanin attenuates paraquat- induced liver toxicity through a mitochondrial pathway. Food Chem. Toxicol. 2014; 70 (14): 100-106.

59- Mohamed RS, Marrez DA, Salem SH, Zaghloul AH, Ashoush IS, Farrage AH. et al.
Hypoglycemic, hypolipidemic and antioxidant effects of green sprouts juice and functional dairy micronutrients against streptozotocininduced oxidative stress and diabetes in rats. Heliyon. 2019; 5 (19): 01197. 